\title{
Effect of nefopam in normal chickens and its relationship to hydrogen peroxide-induced oxidative stress
}

\section{Y.J. Mousa}

Department of Physiology, Biochemistry and Pharmacology, College of Veterinary Medicine, University of Mosul, Mosul, Iraq

\section{Article information}

Article history:

Received April 28, 2020

Accepted May 11, 2020

Available online December 7, 2021

\section{Keywords:}

Analgesia

Chickens

$\mathrm{H}_{2} \mathrm{O}_{2}$

Nefopam

Neurobehaviour

Correspondence:

Y.J. Mousa

yarub204@uomosul.edu.iq

\begin{abstract}
The objective designated to discover the analgesic effect of nefopam in the normal (non-stressed) chickens and its possible alteration due to hydrogen peroxide $\left(\mathrm{H}_{2} \mathrm{O}_{2}\right)$ induced oxidative stress (OS) in 7-14 day old chickens. The analgesia of nefopam has been increased by $47 \%$ in the stressed chickens by measuring the analgesic Median Effective Dose $\left(\mathrm{ED}_{50}\right)$ value. This value was $9.10 \mathrm{mg} / \mathrm{kg}$, IM in the normal chickens where it became $4.80 \mathrm{mg} / \mathrm{kg}$, IM in stressed chickens. There is a significant rise in the antinociceptive action of nefopam $18 \mathrm{mg} / \mathrm{kg}$, IM by $88 \%$ in the stressed group of chickens in comparison with the normal one elicited by an electro-stimulation and formaldehyde $0.05 \mathrm{ml}$ of $0.1 \%$ tests for induction of nociception. The observations showed several significant stimulatory modifications in the neurobehaviour when nefopam treated with a subtle dosage $1 \mathrm{mg} / \mathrm{kg}$, IM in the stressed chickens concerning the latency to move, squares crossed and time of the tonic immobility response test. Significant damage was detected in the liver function when nefopam injected at $18 \mathrm{mg} / \mathrm{kg}$, IM in stress chickens in comparison to normal one by 28,33 and $65 \%$ as estimated through Alkaline phosphatase (ALP), Aspartate trans-aminase (AST) and Alanine trans-aminase (ALT) concentrations in the serum, respectively. The sum of data findings indicated that $\mathrm{H}_{2} \mathrm{O}_{2}$-induced OS increased the analgesic activity of nefopam in the chickens; despite the changes occur on the neurobehaviour and liver function. The dose of nefopam should be reduced when preparing the therapeutic regimen in the stressed animals.
\end{abstract}

DOI: $10.33899 /$ ijvs.2021.127013.1433, , 2021 , College of Veterinary Medicine, University of Mosul.

This is an open access article under the CC BY 4.0 license (http://creativecommons.org/licenses/by/4.0/).

\section{Introduction}

Nefopam is considered a non-narcotic analgesic medication used primarily to treat moderate to severe of acute or chronic nociception and to treat of a neuropathic pain disorder (1). Unlike narcotics; it does not causes addiction, respiratory depression and other deleterious effects related to narcotics therapy (1) and its analgesic activity may be potentiated by acetaminophen coadministration (2). By its centrally acting on the brain and spinal cord, nefopam could produce a better, more profound and reliable analgesia without causing respiratory depression similarly to morphine (1,3-5). Nefopam works by a unique mechanism of action by which it produces analgesia through either modification of $\mathrm{Na}^{+2}$ and $\mathrm{Ca}^{+2}$ canals which decrease glutamate release that considered an important neuro-transmitter associated with noci-ceptive processing or it elevates catecholamines (especially norepinephrine and dopamine) and serotonin activity by inhibiting their reuptake from the presynaptic neurons, which are well-thought-out a pain signaling dependent neurotransmitters $(1,5)$. Many stressful conditions such as chemical $\left(\mathrm{H}_{2} \mathrm{O}_{2}\right)$ and physical (heat) stressors are known to cause modulations in drug response, especially for the centrally acting drugs (11). $\mathrm{H}_{2} \mathrm{O}_{2}$ was previously known to modulate the sedative action of diazepam (6) and xylazine 
(7) and altered the anesthetic properties of ketamine anesthesia in the chickens, which have some deleterious side effects toward the animals (8) in addition to modifying xylazine and diazepam efficacy (9), especially for the drugs with narrow the margin of safety. $\mathrm{H}_{2} \mathrm{O}_{2}$ are well organized to cause OS by increasing reactive $\mathrm{O}_{2}$ species (ROS), thus increases the content of free radicals which interacts and modifies the functions of the cellular components especially the receptor proteins responsible for pharmacodynamics and the cytochrome $\mathrm{P}_{450}$ enzymes responsible for pharmacokinetics $(10,11)$ of the drugs and destruction of the blood-brain barrier (12) and thus altering the drug response.

Because nefopam having no addiction and not causes respiratory depression with efficient analgesia, the purpose of this study consisted of using nefopam as a first report in normal (non-stressed) chickens to determine the beneficial effect of nefopam in the veterinary medicine; despite the possible alteration in the analgesic drug response in case of $\mathrm{H}_{2} \mathrm{O}_{2}$-induced $\mathrm{OS}$ in the stressed chickens.

\section{Materials and methods}

\section{Experimental chickens and chemicals}

Both genders of broiler chickens at 7-14-day-old were used in all the trials which supplied from a local hatchery with a regular body weight between $72-110 \mathrm{~g}$. They were preserved at $30-36^{\circ} \mathrm{C}$, ceaseless light. Experimental chickens have permitted ad libitum to water and ration. Nefopam (1\%, Nefopam chlorhydrate, France) extenuating with a normal saline $(0.9 \% \mathrm{NaCl})$ to be injected intramuscularly (IM) as volume $5 \mathrm{ml} / \mathrm{kg}$.

\section{Ethics}

A methodology for the research and the use of experimental chickens has been authentic by professional committee of the Veterinary Medicine College at the University of Mosul on ethical quality for medical research considerations.

\section{OS status and its induction in the chickens with $\mathrm{H}_{2} \mathrm{O}_{2}$}

One day old chickens were randomly separated into a normal group $\left(\mathrm{H}_{2} \mathrm{O}\right)$ which provided a water whereas the other stress chickens $\left(\mathrm{H}_{2} \mathrm{O}_{2}\right)$ had provided daily fresh $0.5 \%$ $\mathrm{H}_{2} \mathrm{O}_{2}$ (Scharlab, Spain) in drinking water. Prior literatures revealed, incessant $0.5 \% \mathrm{H}_{2} \mathrm{O}_{2} /$ day in water, can induce $\mathrm{OS}$ once assumed for chickens from 1st to 14th-day-old. This treatment pattern of $\mathrm{H}_{2} \mathrm{O}_{2}$ induces $\mathrm{OS}$ at day $7^{\text {th }}, 10^{\text {th }}$ and $14^{\text {th }}$ of chickens confirmed all through by OS biomarkers which were the decrease in glutathione level and the increase of concentrations of malondialdehyde of brain and plasma samples of the chickens by way of OS pointer $(6,8)$. For the above-mentioned reasons; 7-14-days old chickens casted off in the subsequent trials.

\section{Nefopam's ED50 for analgesia of normal and stressed chickens}

The analgesic $\mathrm{ED}_{50}$ value of nefopam was carried out as the first step by ascending and descending way (13) to normal and stressed chicken's groups for choosing the nefopam dosage so that, this dosage will used in the following trials. The initial nefopam dosage at $10 \mathrm{mg} / \mathrm{kg}$, IM $(2,3)$ for both groups of chickens by rise or reduce in the dosage as $3 \mathrm{mg} / \mathrm{kg}$ (not more than $30 \%$ of the initial dose). Nefopam analgesia was determined by using an electrostimulator device (Harvard Apparatus, USA) as paininducing in the chickens $(6,8,11)$. Before and after 30 minutes of nefopam injection, the distress call produced because of noci-ception noted by way of a voltage for every chicken individually. Nefopam considered possesses an anti-nociceptive effect as well as the voltage augmented post-treatment compared to volts recorded pre-treatment which marked as $\mathrm{X}$ and if it is not, it will be designated as O. Subsequent equation casted off to quantify influence of the OS for nefopam's analgesic $\mathrm{ED}_{50}$ : \% OS effect to nefopam's $\mathrm{ED}_{50}=\mathrm{ED}_{50}$ of $\mathrm{H}_{2} \mathrm{O}$ group- $\mathrm{ED}_{50}$ of $\mathrm{H}_{2} \mathrm{O}_{2}$ group/ $\mathrm{ED}_{50}$ of $\mathrm{H}_{2} \mathrm{O}$ group $\times 100$.

The antinociception of nefopam against electrostimulation in normal and stressed chickens

One dose of nefopam was chosen at $18 \mathrm{mg} / \mathrm{kg}$, IM was injected to 6 chickens per $\mathrm{H}_{2} \mathrm{O}$ or $\mathrm{H}_{2} \mathrm{O}_{2}$ groups depending on the previous experiment similar to the analgesic $\mathrm{ED}_{100}$ values of nefopam. The voltage of electro-stimulator apparatus registered pre- and post-thirty min of nefopam therapy to every chicken although the delta volts also noted $(6,7,14-19)$. Over the previously mentioned calculation, the percentage contributed to $\mathrm{H}_{2} \mathrm{O}_{2}$-induced $\mathrm{OS}$ for nefopam's analgesia can be measured by using the delta voltage for $\mathrm{H}_{2} \mathrm{O}$ and $\mathrm{H}_{2} \mathrm{O}_{2}$ groups of chickens.

\section{Antinociceptive effect of nefopam against formaldehyde induced pain sensation in the right paw of normal and stressed chickens}

Nefopam (18 mg/kg, IM) was treated to 6 chickens/group. After 15 minutes of nefopam injection, formaldehyde $(0.1 \%)$ was injected at $0.05 \mathrm{ml}$ in the right paw of both the normal and stressed groups. After 15 minutes of formaldehyde injection to the right paw, the latency of right paw lifting (seconds), a number of right paw lifting and the longer period from lifting to descending of the right paw (duration) (seconds) were documented for 3 minutes for each chick individually as previously described (20).

\section{The neurobehavioral effects of nefopam in normal and stressed chickens}

Different measurements of the open-field activity were used to investigate the acute pattern of the neurobehavioral changes of nefopam in normal and stressed groups (21). 
Activity in open field of all chickens observed 30 minutes afterward nefopam therapy $(1 \mathrm{mg} / \mathrm{kg}$, IM) and this dose did not produce an obvious effect, thus, the subtle effect can be determined to resemble the neurobehavioral deficits (21). Each chicken was positioned alone centrally in field box $(60 \times 60 \times 30 \mathrm{~cm}$ with box floor divided to 16 squares $)$, spreading 50 grams of feed grains on it. Measurements included the subsequent neurobehavioral parameters which observed afterward 30 min of nefopam injection within five minutes interval which included the moving starting in seconds, amount of squares traversed by two legs, an escape jumping, a number of defecations, distress calls and pecking. Afterward, each chicken exposed to examination of tonic immobility (21) by catching every chicken by two hands, setting the chicken at woody surface.

\section{Measurement the ALP, ALT and AST concentrations in normal and stressed chickens treated with nefopam}

Four hours after nefopam therapy at $18 \mathrm{mg} / \mathrm{kg}$, IM, the samples of blood attained of the vein of normal besides stressed groups of chickens (6 chickens/group) and driven in the gel tubes to be centrifuged (Chalice, UK). The gotten samples of serum exploit to estimate serum ALP, AST and ALT (22) levels in Unit/Liter (U/L) which determined using Chemistry analyzer Smart-150 apparatus (Genotek, USA) to determine the possible deleterious effects of nefopam in normal and stressed chickens.

\section{Statistics}

Paired and unpaired student T-test implemented to relate the means of two groups of parametric data whereas the non-parametric data were statistically analyzed by the mann-whitney-U-test (23). Significance accounted of all data stand for $\mathrm{P}<5 \%$.

\section{Results}

\section{Analgesic ED $D_{50}$ of nefopam}

Nefopam analgesic efficacy has been modified and increased in the stressed $\left(\mathrm{H}_{2} \mathrm{O}_{2}\right)$ group of chickens concluded by measuring the analgesic $\mathrm{ED}_{50}$ value of nefopam. The value was at $9.10 \mathrm{mg} / \mathrm{kg}$, IM in the normal $\left(\mathrm{H}_{2} \mathrm{O}\right)$ group while it declined by $47 \%$ in the stressed group of chickens because of the effect of OS induced with $\mathrm{H}_{2} \mathrm{O}_{2}$ to be $4.80 \mathrm{mg} / \mathrm{kg}$, IM as showed in Table 1 .

\section{Analgesic effect of nefopam in normal and stressed chickens \\ Table 2 shows the antinociceptive action of nefopam increased in its efficacy by $88 \%$ in stressed chickens after 30 minutes of nefopam injection at $18 \mathrm{mg} / \mathrm{kg}$ for the effect of $\mathrm{H}_{2} \mathrm{O}_{2}$-induced OS. There is a significantly difference of elevation of post-injection nefopam's anti-nociception and $\Delta$ voltage provoked through electro-stimulation associated to normal group.}

Table 1: Analgesic $\mathrm{ED}_{50}$ value of nefopam in normal and stressed chickens

\begin{tabular}{lcc}
\hline Parameter & \multicolumn{2}{c}{ Result } \\
\cline { 2 - 3 } & Normal group & stressed group \\
\hline ED 50 value $=$ xf $+\mathrm{K} \times \mathrm{d}$ & $9.10 \mathrm{mg} / \mathrm{kg}, \mathrm{IM}$ & $4.80 \mathrm{mg} / \mathrm{kg}, \mathrm{IM}$ \\
Doses extent & $7-13 \mathrm{mg} / \mathrm{kg}$ & $4-10 \mathrm{mg} / \mathrm{kg}$ \\
Early dosage & $10 \mathrm{mg} / \mathrm{kg}$ & $10 \mathrm{mg} / \mathrm{kg}$ \\
Latter dosage (xf) & $9 \mathrm{mg} / \mathrm{kg}$ & $7 \mathrm{mg} / \mathrm{kg}$ \\
K table from (20) & -0.305 & -0.737 \\
\pm in the dose (d) & $3 \mathrm{mg}$ & $3 \mathrm{mg}$ \\
Chickens quantity & $5(X O O X X)^{*}$ & $6(X X O X O X)^{*}$ \\
\hline
\end{tabular}

OS's effect of nefopam's anti-nociceptive $\mathrm{ED}_{50}=$ normal-stressed/normal $\times 100=47 \%$

Plain tab water was given to the normal $\left(\mathrm{H}_{2} \mathrm{O}\right)$ group while $0.5 \% \mathrm{H}_{2} \mathrm{O}_{2}$ in water was supplemented the stressed $\left(\mathrm{H}_{2} \mathrm{O}_{2}\right)$ group from $1^{\text {st }}$ to $14^{\text {th }}$-day-old in chickens' age. ${ }^{*} \mathrm{X}=$ analgesia, $\mathrm{O}=$ no analgesia.

Table 2: Nefopam's analgesia in normal and stress chickens models

\begin{tabular}{lcccc}
\hline Variable & Anti-nociception $\%$ & Pre-therapy volts & Post-therapy volts & $\Delta$ Voltage \\
\hline Normal $\left(\mathrm{H}_{2} \mathrm{O}\right)$ group & $100(6 / 6)$ & $8.17 \pm 0.54$ & $12.33 \pm 0.71^{\mathrm{a}}$ & $4.17 \pm 0.31$ \\
Stressed $\left(\mathrm{H}_{2} \mathrm{O}_{2}\right)$ group & $100(6 / 6)$ & $9.17 \pm 0.48$ & $17.73 \pm 0.73^{*}$,a & $7.83 \pm 0.40^{*}$ \\
\hline \multicolumn{4}{l}{ OS's effect for nefopam's analgesia $=\Delta$ stressed- $\Delta$ normal $/ \Delta$ normal $\times 100=88 \%$} &
\end{tabular}

Numbers denoted mean \pm Std.Err. $0.5 \% \mathrm{H}_{2} \mathrm{O}_{2}$ in water was supplemented the stressed $\left(\mathrm{H}_{2} \mathrm{O}_{2}\right)$ group from $1^{\text {st }}$ to $14^{\text {th }}$-day-old in chickens' age. Post-injection record of volts was after 30 minutes of nefopam was injected at $18 \mathrm{mg} / \mathrm{kg}$, IM for both the normal and stressed groups. * Differ significantly as of the normal chickens $(\mathrm{P}<5 \%)$. A differ significantly as of pre-therapy at the similar group of chickens $(\mathrm{P}<5 \%)$. 
Nefopam's antinociception against formaldehyde induced pain sensation in the right paw of normal and stressed chickens

A significant augmentation in the nefopam antinociceptive efficacy was noticed in the stressed chickens compared to the normal chickens as presented by recording the latency of right paw lifting, it's lifting number and the duration of the right paw lifting that injected with the irritant formaldehyde (Table 3).

\section{Neurobehavioral effects of nefopam in normal and stressed chickens}

Administration of nefopam by subtle $(1 \mathrm{mg} / \mathrm{kg}, \mathrm{IM})$ dosage causes different significant neurobehavioral changes in the stressed chickens concerning the beginning of moving in seconds.

An amount of squares intersected with two legs and the time of the tonic immobility response test in seconds while there is a slight difference on a number of defecation, numbers of escape jumps and pecking behaviour which refer to rise in the subtle stimulant effect of nefopam in stressed chickens compared to the normal chickens as noticed in Table 4.

Serum ALP, ALT and AST concentrations for determination of liver function in normal and stressed chickens treated with nefopam

Table 5 demonstrated there is significantly differs of elevation of ALP, ALT and AST concentrations of serum the stressed chickens by 28,65 and $33 \%$ when compared to the normal group of chickens that both treated with nefopam at $18 \mathrm{mg} / \mathrm{kg}$, IM which shows the serious deleterious effect on the liver function due to the effect of $\mathrm{H} 2 \mathrm{O} 2$-induced OS criteria in the stressed chickens.

Table 3: Antinociceptive effect of nefopam against formaldehyde induced pain sensation in the right paw of normal and stressed chickens

\begin{tabular}{lccc}
\hline Groups & $\begin{array}{c}\text { Latency of the right paw } \\
\text { lifting (seconds) }\end{array}$ & $\begin{array}{c}\text { Number of the right paw } \\
\text { lifting }\end{array}$ & $\begin{array}{c}\text { Duration of the right paw lifting } \\
\text { (seconds) }\end{array}$ \\
\hline Normal $\left(\mathrm{H}_{2} \mathrm{O}\right)$ group & $19.50 \pm 2.20$ & $15.67 \pm 1.57$ & $1.47 \pm 0.21$ \\
Stressed $\left(\mathrm{H}_{2} \mathrm{O}_{2}\right)$ group & $48.10 \pm 4.67^{*}$ & $3.43 \pm 0.19^{*}$ & $1.00 \pm 0.00^{*}$ \\
\hline
\end{tabular}

Numbers denoted mean \pm Std.Err. $0.5 \% \mathrm{H}_{2} \mathrm{O}_{2}$ in water was supplemented the stressed $\left(\mathrm{H}_{2} \mathrm{O}_{2}\right)$ group from $1^{\text {st }}$ to $14^{\text {th }}$-day-old in chickens' age. Formaldehyde $(0.05 \mathrm{ml}$ of $0.1 \%)$ was injected in the right paw after 15 minutes of nefopam injection at 18 $\mathrm{mg} / \mathrm{kg}$, IM. The above data recorded after 30 minutes of nefopam injection for 3 minutes. * Differ significantly as of the normal chickens $(\mathrm{P}<5 \%)$.

Table 4: Nefopam's neurobehavioral deficits at normal along with stress chickens

\begin{tabular}{lcc}
\hline Neurobehavioral Parameters & \multicolumn{2}{c}{ Groups } \\
\cline { 2 - 3 } & Normal group & Stressed group \\
\hline Latency to move (seconds) & $11.33 \pm 0.49$ & $5.17 \pm 1.25^{*}$ \\
Number of squares crossed by both legs & $29.83 \pm 2.85$ & $47.17 \pm 3.56^{*}$ \\
Tonic immobility response (seconds) & $4.50 \pm 0.34$ & $2.33 \pm 0.21^{*}$ \\
Number of defecation & $0.33 \pm 0.21$ & $0.67 \pm 0.21$ \\
Number of escape jumps & $0.67 \pm 0.21$ & $1.00 \pm 0.37$ \\
Distress-calls & $3.00 \pm 0.00$ & $3.00 \pm 0.00$ \\
Pecking scores & $0.67 \pm 0.21$ & $1.33 \pm 0.33$ \\
\hline
\end{tabular}

The values denoted Mean \pm S.E. $0.5 \% \mathrm{H}_{2} \mathrm{O}_{2}$ in water was supplemented the stressed $\left(\mathrm{H}_{2} \mathrm{O}_{2}\right)$ group from $1^{\text {st }}$ to $14^{\text {th }}$-day-old in chickens' age. Open field activity was recorded after 30 minutes of nefopam injection at $1 \mathrm{mg} / \mathrm{kg}$, IM for both the normal besides stress groups. * Differ significantly as of the normal chickens $(\mathrm{P}<5 \%)$.

Table 5: Serum ALP, ALT and AST concentrations in normal and stressed chickens treated with nefopam

\begin{tabular}{lccc}
\hline Variable groups & ALP $(\mathrm{U} / \mathrm{L})$ & ALT $(\mathrm{U} / \mathrm{L})$ & AST $(\mathrm{U} / \mathrm{L})$ \\
\hline Normal $\left(\mathrm{H}_{2} \mathrm{O}\right)$ group & $227.50 \pm 1.88$ & $12.33 \pm 0.61$ & $216.00 \pm 3.79$ \\
Stressed $\left(\mathrm{H}_{2} \mathrm{O}_{2}\right)$ group & $292.00 \pm 4.34^{*}$ & $20.33 \pm 0.76^{*}$ & $287.67 \pm 3.65^{*}$ \\
Effect of $\mathrm{OS}$ on liver function parameters & 28 & 65 & 33 \\
$(\%)=$ stressed-normal/normal×100 & & & 33 \\
\hline
\end{tabular}

The values denoted Mean \pm S.E. $0.5 \% \mathrm{H}_{2} \mathrm{O}_{2}$ in water was supplemented the stressed $\left(\mathrm{H}_{2} \mathrm{O}_{2}\right)$ group from $1^{\text {st }}$ to $14^{\text {th }}$-day-old in chickens' age. Nefopam was injected at $18 \mathrm{mg} / \mathrm{kg}$, IM. * Differ significantly as of the normal chickens $(\mathrm{P}<5 \%)$. 


\section{Discussion}

The purpose of this study consisted from using nefopam as a first report in normal (non-stressed) chickens to determine the beneficial effect of nefopam in the veterinary medicine; despite the possible alteration in the analgesic drug response in case of $\mathrm{H}_{2} \mathrm{O}_{2}$-induced $\mathrm{OS}$ in the stressed chickens because nefopam having no addiction and not causes respiratory depression with efficient analgesia (1). Nefopam primarily used to treat moderate-to-severe acute or chronic nociception (1) and to treat of the neuropathic pain disorders $(1,24)$ and postoperative pain therapy (1) through its central action on the central nervous system (CNS). As noticed, the central antinociceptive effect of nefopam was increased in efficacy in the stressed chickens $\left(0.5 \% \mathrm{H}_{2} \mathrm{O}_{2}\right.$ added to their water) compared to the normal chickens (supplied with tap water) concerning $\mathrm{ED}_{50}$ value, electro-stimulation and formaldehyde induced pain sensation. This trial used $\mathrm{H}_{2} \mathrm{O}_{2}$ as a well-known powerful oxidant for inducing of OS experimentally (6). Nefopam has been selected because of its centrally acting mechanism by which it produces analgesia through either modification of $\mathrm{Na}^{+2}$ and $\mathrm{Ca}^{+2}$ canals which diminish the glutamate releasing elaborate in nociceptive handling or it elevates norepinephrine, dopamine and serotonin activity by inhibiting their reuptake from the presynaptic neurons are considered in pain signaling $(1,7)$. The CNS-acting drugs were found to be the most altered in pharmacological response due to the OS status that induced by $\mathrm{H}_{2} \mathrm{O}_{2}$ because of its ability to destruct the Blood-Brain Barrier (15) and thus making the CNS receptors more vulnerable to high drug concentration and later augmented the drug affinity and efficacy as these findings agree with earlier studies in the same field (9-12).

Other reasons implemented to the increase of the nefopam efficacy refers to $\mathrm{H}_{2} \mathrm{O}_{2}$ ability to cause $\mathrm{OS}$ by elevating ROS; thus increases the free radicals formation which interacts and alters the functions of the cellular components especially the receptor proteins that involved in drug pharmacodynamics (affinity and efficacy), its destruction of the cytochrome $\mathrm{P}_{450}$ enzymes (which delay the excretion of the nefopam and elevating its plasma concentration) and the damage proposed to the specific nefopam protein binding which all responsible for drug pharmacokinetics and disposition (10,11). Nefopam treatment at a subtle dose was found to cause stimulation of the central nervous system; leading to a stimulatory neurobehavioral effect in the chickens when examined at the open-field activity test with an enhanced stimulatory effect in the stressed chickens that may be referred to as receptor up-regulation because of OS status (24) or an increase in the release of the excitatory neurotransmitters (catecholamines) due to cellular damage that evokes a synergistic interaction to the nefopam mechanism of action. The serum ALP, ALT and AST concentrations in the normal $\left(\mathrm{H}_{2} \mathrm{O}\right)$ group of chickens were found in normal ranges in the chicken as mentioned in the other study (25) and due to the ability of the $\mathrm{H}_{2} \mathrm{O}_{2}$ to cause cellular damage (like proteins), the liver function will also be affected which were found here through measuring the level of serum ALT, AST, and ALP concentrations in the stressed chickens and compare it to the normal one.

\section{Conclusion}

The sum of data findings indicated that $\mathrm{H}_{2} \mathrm{O}_{2}$-induced OS increased the analgesic activity of nefopam in the chickens; despite the changes occur on the neurobehaviour and liver function. The dose of nefopam should be reduced when preparing the therapeutic regimen in the stressed animals.

\section{Acknowledgements}

Gratitude to the support, opportuneness of tools and supplies used in this study to the Veterinary Medicine College which have its place in the University of Mosul.

\section{Conflict of interest}

The authors declare there is no conflict of interest.

\section{References}

1. Girard P, Chauvin M, Verleye M. Nefopam analgesia and its role in multimodal analgesia: A review of preclinical and clinical studies. Clin Exper Pharmacol Physiol. 2016;43(1):3-12. DOI: 10.1111/1440$\underline{1681.12506}$

2. Li Q, Zhuang Q, Gu Y, Dai C, Gao X, Wang X, Wen H, Li X, Zhang Y. Enhanced analgesic effects of nefopam in combination with acetaminophen in rodents. Biomed Rep. 2018;8:176-183. DOI: 10.3892/br.2017.1032

3. Zanjani TM, Saghaei E, Ameli H, Sabetkasaei M. Anti-allodynic effect of nefopam and morphine in rat model of neuropatheic pain. Nov Biomed. 2013;1:16-22. DOI: 10.22037/nbm.v1i1.4488

4. Kapfer B, Alfonsi P, Guignard B, Sessler DI, Chauvin M. Nefopam and ketamine comparably enhance postoperative analgesia. Anesth Analg. 2005;100(1):169-174. DOI: 10.1213/01.ANE.0000138037.19757.ED

5. Kang P, Park SK, Yoo S, Hur M, Kim WH, Kim JT, Bahk JH. Comparative effectiveness of pharmacologic interventions to prevent shivering after surgery: a network meta-analysis. Minerva Anestesiol. 2019;85(1):60-70. DOI: 10.23736/S0375-9393.18.12813-6

6. Mousa YJ. Etomidate anesthesia in chicks: Effect of xylazine. J Hellen Vet Med Soc. 2020;71(4):2463-2470. DOI: 10.12681/jhvms.25921

7. Mousa YJ, Mohammad FK. The analgesic efficacy of xylazine and dipyrone in hydrogen peroxide-induced oxidative stress in chicks. Iraq J Vet Sci. 2012;26(2):69-76. DOI: 10.33899/ijvs.2012.67444

8. Mousa YJ. Anaesthetic properties of ketamine in chicks stressed with hydrogen peroxide. Vet Med. 2014;59(8):369-375. DOI: 10.17221/7656-VETMED

9. Mousa YJ, Mohammad FK. Effects of hydrogen peroxide on diazepam and xylazine sedation in chicks. Interdiscip Toxicol. 2012;5(4):179183. DOI: 10.2478/v10102-012-0030-5

10. Lee KJ, Jeong HG. Protective effect of kahweol and cafestol against hydrogen peroxide-induced oxidative stress and DNA damage. Toxicol Lett. 2007;173:80-87. DOI: 10.1016/j.toxlet.2007.06.008 
11. Nita M, Grzybowski A. The Role of the Reactive Oxygen Species and Oxidative Stress in the Pathomechanism of the Age-Related Ocular Diseases and Other Pathologies of the Anterior and Posterior Eye Segments in Adults. Oxid Med Cell Long. 2016;2016:3164734. DOI: $10.1155 / 2016 / 3164734$

12. Lochhead JJ, McCaffrey G, Quigley CE, Finch J, DeMarco KM, Nametz N, Davis TP. Oxidative stress increases blood-brain barrier permeability and induces alterations in occludin during hypoxiareoxygenation. J Cereb Blood Flow Met. 2010;30:1625-1636. DOI: $10.1038 / \mathrm{jcbfm} .2010 .29$

13. Dixon WJ. Efficient analysis of experimental observations. Annu Rev Pharmacol Toxicol. 1980;20:441-462 DOI: 10.1146/annurev.pa.20.040180.002301

14. Mousa YJ, Al-Zubaidy MHI. Anesthetic efficacy of ketamine, ketamine-tramadol and ketamine-ketorolac in the chicks. Iran J Vet Res. 2019;20(1):33-38. DOI: 10.22099/ijvr.2018.29755.4496

15. Mousa YJ. Analgesic, antipyretic and anti-inflammatory efficacy of ketorolac in the chicks. Ind J Anim Sci. 2019;89(10):1086-1090. [available at]

16. Mousa YJ, Mahmood MB, Mohammad MS. Administration of ketamine with the central and peripheral analgesics for induction of balanced anesthesia in the chicks. Earth Environ Sci. 2019;388:012021. DOI: 10.1088/1755-1315/388/1/012021

17. Shaban KhA, Ibrahim MH, Faris GA. Evaluation of the antinociceptive effect of xylazine and it's interaction with metoclopramide in the acute pain model in mice. Iraqi J Vet Sci. 2020;34(2):383-388. DOI: 10.33899/ijvs.2019.126070.1226

18. Mousa YJ, Al-Zubaidy MH, Amin SM. Age-related anesthetic effect of ketamine in the chickens. Iraqi J Vet Sci. 2021;35(3): DOI: 10.33899/ijvs.2020.127100.1458

19. Al-abdaly YZ, Saeed MG, Al-Hashemi HM. Effect of methotrexate and aspirin interaction and its relationship to oxidative stress in rats. Iraqi J Vet Sci. 2021;35(1):151-156. DOI: 10.33899/ijvs.2020.126490.1335

20. Sufka KJ, Roach JT, Chambliss Jr WG, Broom SL, Feltenstein MW, Wyandt CM, Zeng L. Anxiolytic properties of botanical extracts in the chick social separation-stress procedure. Psycopharmacol. 2001;153:219-224. DOI: 10.1007/s002130000571

21. Mohammad FK, Mousa YJ, Hasan, MM. Acute toxicity and neurobehavioral effects of diphenhydramine in chicks. J Poult Sci. 2012;49(1):51-56. DOI: 10.2141/jpsa.011050

22. Reitman S, Frankel S. A colorimetric method for the determination of serum glutamic oxaloacetic and glutamic pyruric transaminase. Am J Clin Path. 1957;28:56-63. DOI: 10.1093/ajcp/28.1.56

23. Katz MH. Multivariable analysis: A practical guide for clinicians and public health researchers. New York: Cambridge University Press; 2011. 14-74 p. [available at]

24. Kim KH, Abdi S. Rediscovery of nefopam for the treatment of neuropathic pain. Kor J Pain. 2014;27(2):103-111. DOI: 10.3344/kjp.2014.27.2.103

25. Cruz CE, Freitas ER, Braz NM, Salles RP, da Silva ING. Blood parameters and enzymatic and oxidative activity in the liver of chickens fed with calcium anacardate. Rev Cien Agron. 2018;49(2):343-352. DOI: $\underline{10.5935 / 1806-6690.20180039}$

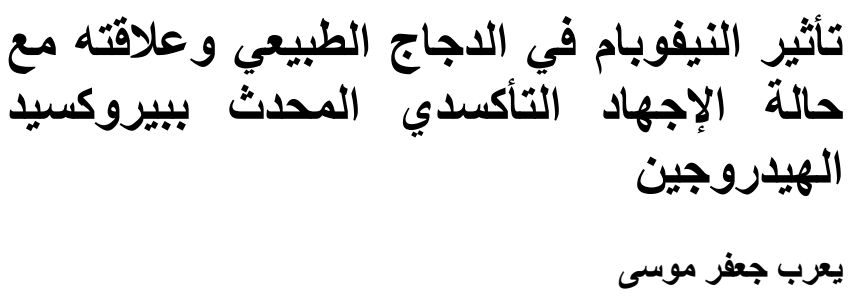

فرع الفسلجة و الكيمياء الحياتية والأدوية، كلية الطب البيطري، جامعة

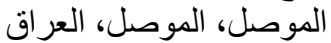

الخلاصة

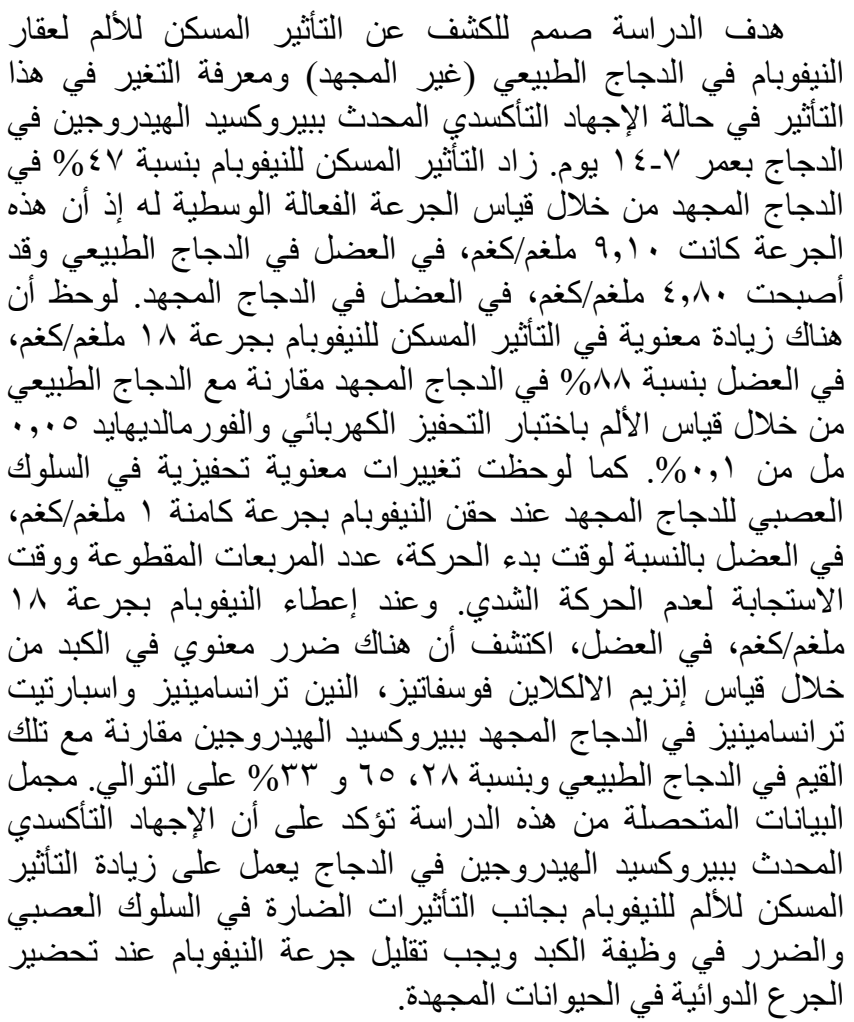

